Minireview

\title{
Membrane biogenesis in anoxygenic photosynthetic prokaryotes
}

\author{
Gerhart Drews ${ }^{1}$ \& Robert A. Niederman ${ }^{2, *}$ \\ ${ }^{1}$ Institut für Biologie 2, Mikrobiologie, Albert-Ludwigs-Universität, Schänzlestrasse 1, D-79104 Freiburg, \\ Germany; ${ }^{2}$ Department of Molecular Biology and Biochemistry, Rutgers University, Piscataway, \\ NJ 08854-8082, USA; *Author for correspondence (e-mail: rniderm@ rci.rutgers.edu; fax: +1-732-445-4213)
}

Received 15 August 2001; accepted in revised form 29 November 2001

Key words: G. Cohen-Bazire, light harvesting complexes, B.L. Marrs, membrane development, H. Molisch, D. Oesterhelt, photosynthetic bacteria, photosynthetic membranes, reaction center complexes, R.Y. Stanier. C.B. van Niel

\begin{abstract}
Following the discovery of photosynthetic bacteria in the nineteenth century, technical developments of the 1950s led to their use in membrane biogenesis studies. These investigations had their origins in the isolation of subcellular particles designated as 'chromatophores' by Roger Stanier and colleagues, which were shown to be photosynthetically competent by Albert Frenkel, and to originate from the intracytoplasmic membrane (ICM) continuum observed in electron micrographs. These ultrastrucutral studies by the G. Drews group, Germaine Cohen-Bazire and others also suggested that the ICM originates by invagination of the cytoplasmic membrane, as later established in the biochemical and biophysical work of the R. Niederman and Drews groups. Through a combination of genetic approaches, first introduced in the early 1980s by Barry Marrs, and the atomic resolution structures determined for light-harvesting antennae and reaction centers, a detailed understanding is emerging of mechanisms regulating their levels in the membrane and the roles played by specific protein domains and additional factors in their assembly and supramolecular organization. Prospects for additional progress during the twenty-first century include further elucidation of molecular aspects of the assembly process and the application of newer spectroscopic probes to photosynthetic unit formation.
\end{abstract}

Abbreviations: $\quad b c_{1}$ complex - ubiquinonol-cytochrome $c_{2}$ oxidoreductase; ICM - intracytoplasmic membranes; LH 1 - core light-harvesting complex; LH 2 - peripheral light-harvesting complex; UQ - ubiquinol

\section{Early research on bacterial photosynthetic membranes}

Although photosynthesis in green plants was described in the late eighteenth century, it was not until a century later that the purple bacteria, first described by Christian Gottfried Ehrenberg (1838), Edwin Lankester (1873) and Ferdinand Cohn (1875), were postulated from phototaxis studies by Wilhelm Engelmann (1888) to transform light energy into chemical energy [for references to these early papers, see Drews (2000)]. The anoxygenic nature of bacterial photosynthesis was established by Hans Molisch
(1907), and it was found that the source of reducing potential could arise from the oxidation of an organic or inorganic reductant $\mathrm{H}_{2} \mathrm{~A}$, rather than from the photolysis of $\mathrm{H}_{2} \mathrm{O}$ as in higher phototrophs; this important distinction was first postulated by Cornelis (Kees) van Niel (1931).

Intracytoplasmic membranes are the site of the bacterial photosynthetic apparatus

As detailed in a review by Robert Niederman (Figure 1) and Ken Gibson (Niederman and Gibson 1978), the development of cell fractionation techniques by Roger Stanier and his colleagues in the early 1950s 


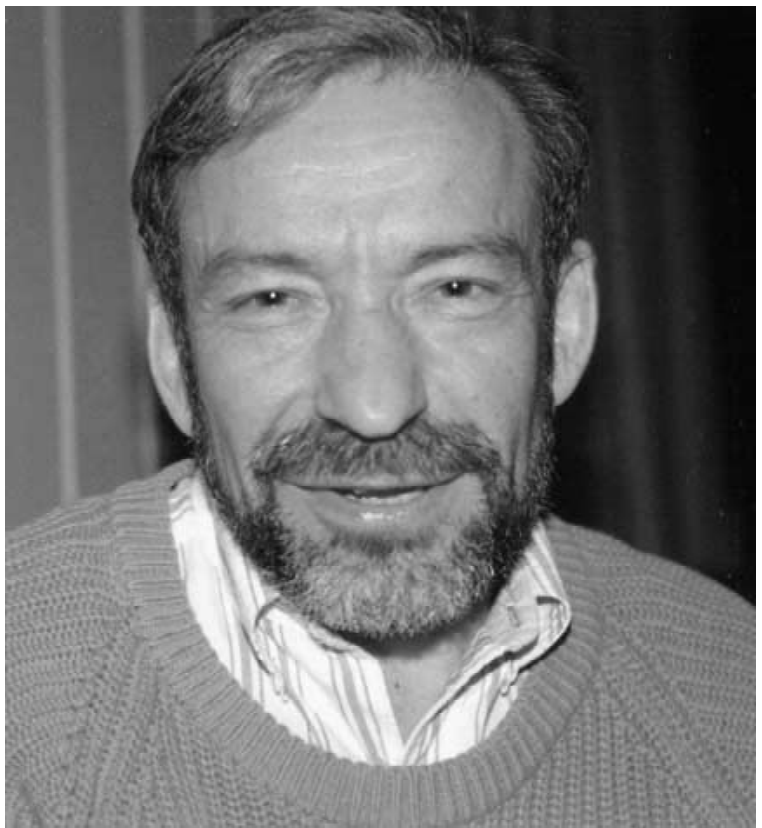

Figure 1. Robert Niederman.

established that the photosynthetic apparatus of anoxygenic photosynthetic prokaryotes could be isolated as a discrete particulate fraction. These pigmented particles, designated then as 'chromatophores', were soon shown by Albert Frenkel (1954) to catalyze photophosphorylation and light-dependent reductions.

Ultrastructural observations by Gerhart Drews (Figure 2) (reviewed by Drews 1996a), Germaine Cohen Bazire and others, over the next decade, showed that 'chromatophores' arise from internal vesicular, tubular, or lamellar structures of different cellular organization. Jürgen Oelze and Drews (1972) replaced 'chromatophore' with the more general and descriptive term, intracytoplasmic membrane (ICM), which forms a membrane continuum of vesicles or flat membrane sacs connected by thin tubules. Consistent with its prokaryotic nature, the ICM originates by invagination from the cytoplasmic membrane (CM) or preformed intracytoplasmic vesicles, rather than de novo.

\section{Morphogenesis of the intracytoplasmic membrane}

Many facultative nonsulfur purple bacteria grow chemotrophically in the dark or phototrophically in the light in the absence of oxygen, adapting by cell differentiation. Their bacteriochlorophyll (BChl) contents and ICM levels are related inversely to oxygen

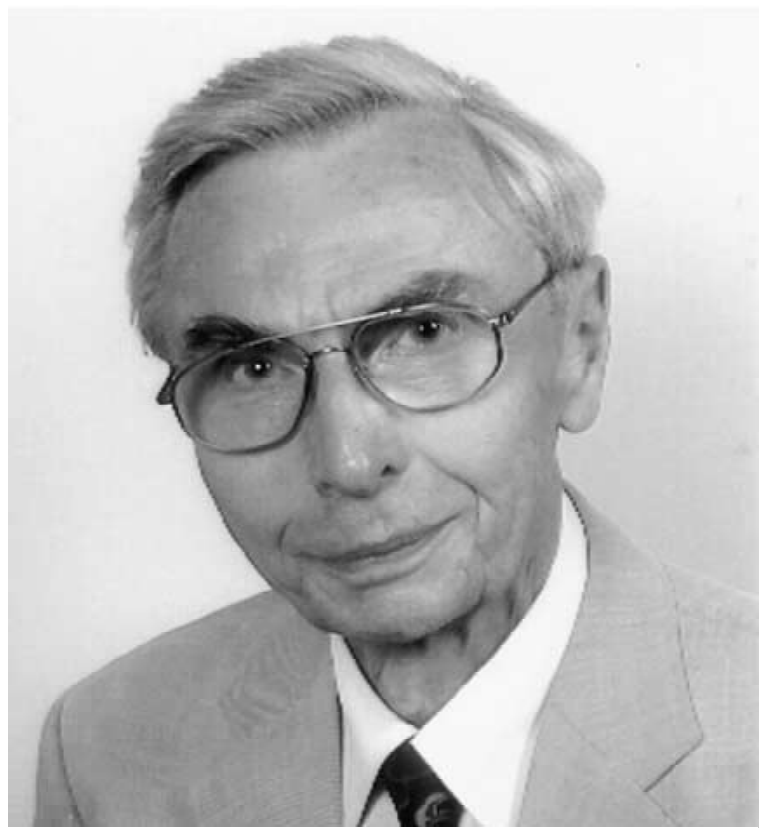

Figure 2. Gerhart Drews.

partial pressure and light intensity (Drews and Golecki 1995; Drews 1996a). Although Rubrivivax gelatinosus and Rhodocyclus tenuis form little ICM, they adjust to conditions that derepress the photosynthetic apparatus by enlarging the $\mathrm{CM}$ area and through a higher density of photosynthetic units.

\section{Composition of cytoplasmic and intracytoplasmic membranes}

Cell fractionation and density gradient centrifugation techniques, developed to separate different membrane fractions, soon suggested that the major portion of the photosynthetic apparatus is present in the ICM fraction, while the CM is enriched in respiratory activity (reviewed by Niederman and Gibson 1978). This was verified by protein patterns in Sodiumdodecyl-sulphate-(SDS)-polyacrylamide gel electrophoresis and enzymatic activities. At about the same time, the lipids of the ICM were found to consist mainly of the phospholipids phosphatidylethanolamine, phosphatidylglycerol and phospatidylcholine.

\section{The functional complexes of membranes}

\section{Visualization in freeze-fracture electron microscopy}

Using freeze-fracture techniques in which the lipid bilayer is split, exposing the internal architecture of the membrane, a pattern of regularly arranged, $\sim 100$ 
$\AA$ intramembrane particles was observed in the ICM of Blastochloris viridis (see Drews and Golecki 1995). The fracture faces of membranes from Rhodospirillum, Rhodobacter, and Rhodocyclus species were densely packed with particles of varying size and number that were correlated with the state of membrane morphogenesis. These parameters remained relatively constant in the CM of Rhodospirillum rubrum and Rhodobacter sphaeroides, which is largely undifferentiated in these species and where membrane differentiation leads to ICM formation. As shown in Andrew Staehelin's laboratory, for lamellae of Rp. palustris, intramembrane particle size distribution is spatially differentiated with regions of very high particle density confined mainly to large stacks of ICM and those of lower density limited to unstacked CM.

\section{Isolation and characterization of reaction-center and light-harvesting complexes}

Once methods were developed to release pigmentprotein complexes from the membrane with mild detergents and to purify them by ultracentrifugation and chromatographic procedures, important new structural and functional insights began to emerge. Reaction centers were isolated from $R b$. sphaeroides by Roderick Clayton's group (Reed and Clayton 1968; see Clayton, this issue), soon followed by the isolation of the peripheral light-harvesting (LH) complex 2 (Clayton and Clayton 1972). Electrophoretic methods were established for the isolation of the core antenna, LH 1, from $R b$. sphaeroides by Niederman and coworkers (Broglie et al. 1980), and the amino acid sequences of the LH apoproteins were determined after extraction with organic solvent and chromatographic purification by the group led by Herbert Zuber (Zuber 1990).

\section{Molecular genetics of anoxygenic phototrophs}

The description by Barry Marrs (Marrs 1981) of a gene transfer agent in $R b$. capsulatus paved the way for molecular genetic approaches in photosynthetic bacteria (see B.L. Marrs, this issue). The nucleotide and deduced polypeptide sequences of several proteins of the photosynthetic gene cluster, including the three reaction-center subunits and the LH $1-\alpha$ and $-\beta$ polypeptides, were soon completed in John Hearst's laboratory (Youvan et al. 1984). The deduced polypeptide sequences for the cytochrome $b c_{1}$ complex (ubiquinonol-(UQ)-cytochrome$c_{2}$-oxidoreductase) were subsequently determined in
Fevzi Daldal's laboratory (Davidson and Daldal 1987).

The photosynthetic gene cluster is organized into large superoperons, expressed selectively in response to oxygen partial pressure and light intensity, which link the pigment biosynthesis operons with operons encoding light-harvesting and reaction center proteins. As established by Carl Bauer and others, this level of regulation involves transcriptional activators belonging to the two-component family of prokaryotic regulators (Bauer et al. 1993).

\section{A detailed picture of the membrane assembly process is emerging}

\section{Atomic-resolution structures of BChl-protein complexes}

Elucidation of the high-resolution structures of the bacterial reaction center by Hans Deisenhoffer, Hartmut Michel, and Robert Huber (Deisenhofer et al. 1985) and the LH 2 complex by Richard Cogdell and collaborators (McDermott et al. 1995) has brought about considerable progress in understanding the primary photosynthetic events and the structural organization of the membrane components catalyzing them. Best characterized are the type II reaction centers of the purple bacteria $B$. viridis and $R b$. sphaeroides, which contain the $\mathrm{L}$ and $\mathrm{M}$ polypeptide homologs of the D1 and D2 subunits of Photosystem II, and bind the $\mathrm{BChl}$, bacteriopheophytin, quinone, and other cofactors.

The atomic-resolution structure of the LH 2 complex of Rhodopseudomonas acidophila (McDermott et al. 1995) revealed a ring of $18 \mathrm{~B} 850 \mathrm{BChls,} \mathrm{sand-}$ wiched between cylindrical assemblies of the transmembrane $\alpha$-helices of the $\alpha$ - and $\beta$-apoproteins making up the respective inner and outer walls. The B800 BChls are positioned on the outer surface while the carotenoid molecule is closely associated with the BChls. Such an annular arrangement facilitates the rapid delocalization of excitations and their ultimate delivery to the reaction center. Electron diffraction analysis of two-dimensional crystals of the Rs. rubrum LH 1 by Robin Ghosh and collaborators (Karrasch et al. 1995) has demonstrated that this complex consists of a larger annular structure with 32 BChls, which is sufficiently large to surround a single reaction center.

Figures 3 and 4 are group photographs of some of the researchers in 1991 and 1996, respectively. Figure 

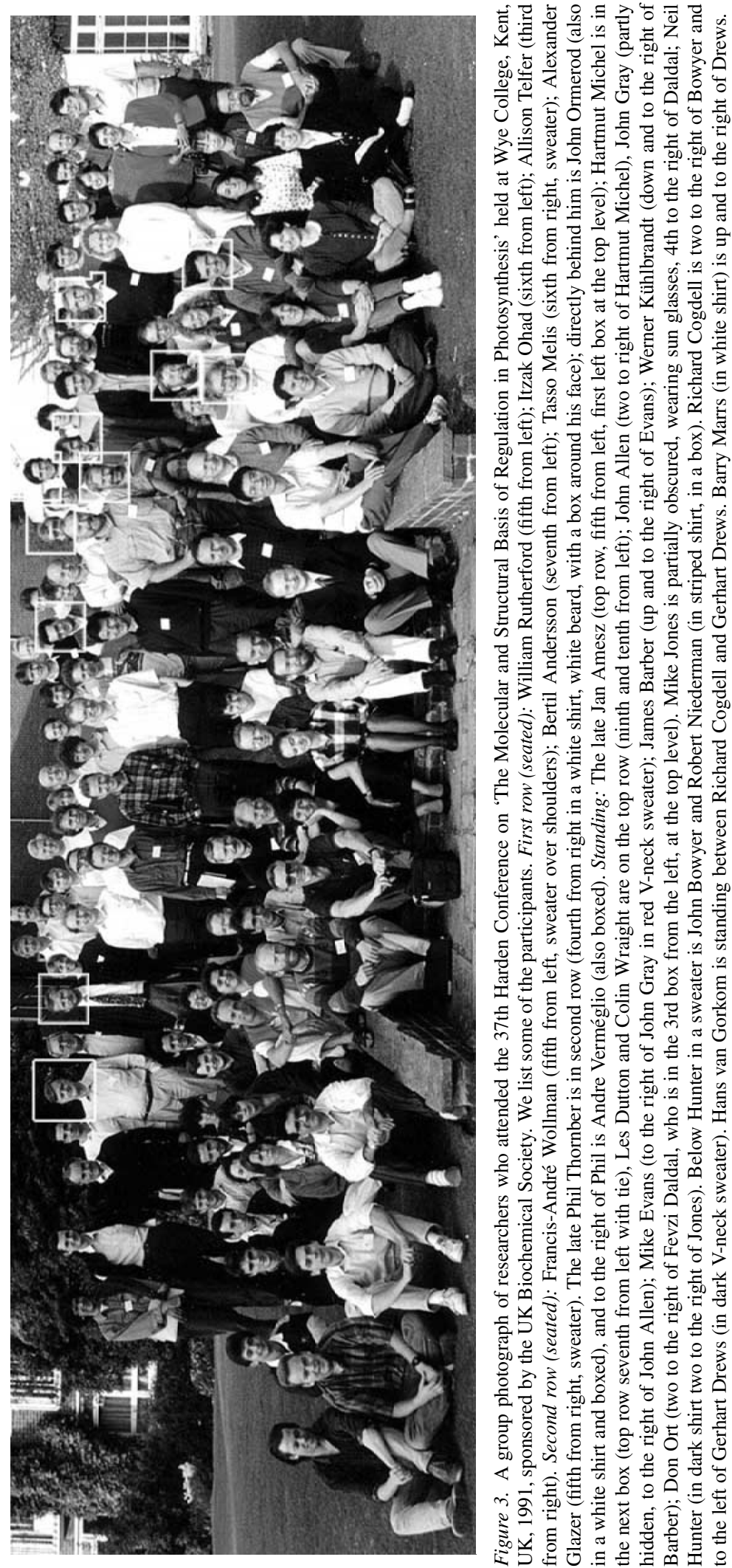


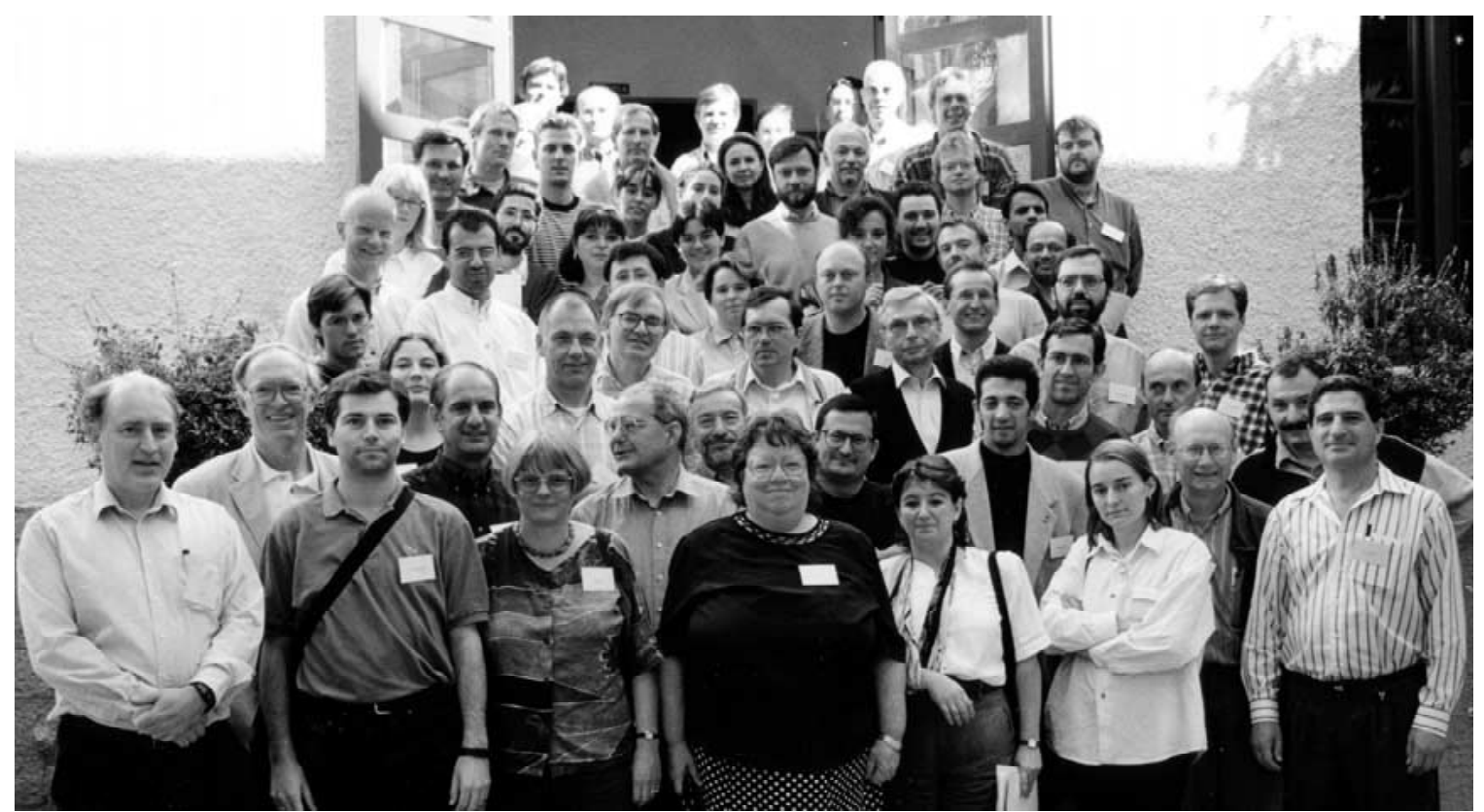

Figure 4. A photograph of some of the contributors to research, who attended the European Science Foundation Workshop on 'Molecular Recognition in Photosynthesis' held in Jaca, Spain in 1996. We list here only some of the participants. The readers are encouraged to make their own list. Rafael Picorel, the organizer, is on the extreme right in the first row. In the first row, we see John Allen (first on the left); Mette Miller (third); Elizabeth Gross (fourth); Paul Mathis is directly to left of Rafael. In the second row, we see Neil Isaacs (first on the left) and Hugo Scheer (third in from the left); Bob Niederman is directly to the right of Hugo; Gerhart Drews (in dark V-neck sweater) is two to the right of Bob; and John Gray is directly up from Hugo. Next to John Gray is Imre Vass. The photograph is not very clear in the back. Those who look carefully may find Neil Hunter, André Verméglio, Dieter Oesterhelt, Gyozo Garab, Matthias Rögner and Parag Chitnis.

3 is of those who attended the 37th Harden Conference on 'The Molecular and Structural Basis of Regulation in Photosynthesis' held at Wye College, Kent, UK, whereas Figure 4 is of those who attended the European Science Foundation Workshop on 'Molecular Recognition in Photosynthesis' held in Jaca, Spain. These show some of those mentioned above (Hartmut Michel, Fevzi Daldal, Richard Cogdell, Robert Niederman, and Gerhart Drews, among others) as well as other pioneers in the field.

\section{Molecular aspects of membrane biosynthesis}

\section{Membrane assembly in vivo}

After a shift from chemotrophic to phototrophic conditions, photosynthetic units are incorporated into the $\mathrm{CM}$ and growing ICM, as reflected in the altered intramembrane particle distributions, protein patterns, fluorescence properties, and enzymatic activities in distinct membrane domains (Drews and Golecki 1995). From pulse-chase studies and biophysical measurements by the Niederman group, newly synthesized photosynthetic units were found to be enriched in a pigmented membrane band that sediments more slowly than ICM vesicles in sucrose gradients. This upper pigmented band had the properties of immature CM invaginations, which give rise to the ICM at the cell periphery (Bowyer et al. 1985). This system should prove useful for studies with new spectroscopic probes of development, such as IR-fast repetition rate fluorometry (Kolber et al. 2000) and single particle analyses by time-resolved fluorescence microscopy.

$R b$. sphaeroides mutants lacking LH 2 have been shown by the Niederman group (Hunter et al. 1988) and in Sam Kaplan's laboratory (Kiley et al. 1988) to form tubular rather than vesicular ICM, suggesting that LH 2 has a role in ICM morphogenesis. Kaplan et al. (1983) have also shown that phospholipids, synthesized in the CM, are transferred to the ICM by an apparent phospholipid transfer protein at the time of cell division, while proteins and pigments are inserted into CM and ICM throughout the cell cycle. As a consequence, during the cell cycle, the protein/phospholipid ratio fluctuates along with the rate of cyclic electron flow and the numbers of photosynthetic units in the ICM. 


\section{The assembly of integral membrane complexes}

Reaction center and LH polypeptides are inserted into the membrane without cleavable N-terminal signal peptides. ${ }^{1}$ LH apoproteins become oriented with amino-terminal regions at the cytoplasmic side of the membrane and carboxyl-termini exposed to the periplasmic side. Formation of a stable oligomeric LH 1 complex requires both the $\alpha$ - and the $\beta$-subunits, encoded by pufA and pufB genes (Drews 1996b). The N-terminal regions of LH $1-\alpha$ and $-\beta$ interact during assembly, which aids in forming the correct oligomeric structure of the complex.

In addition to the $\alpha$ - and $\beta$-polypeptides encoded by $p u c \mathrm{~A}$ and $p u c \mathrm{~B}, R b$. capsulatus LH 2 contains a third polypeptide, $\gamma$ (PucE), which stabilizes the complex, but is unnecessary for its formation or function. An additional gene (PucC) is essential for expression of the puc operon in both $R b$. capsulatus (Tichy et al. 1991) and $R b$. sphaeroides (Gibson et al. 1992). Although the $\alpha$ - and $\beta$-polypeptides of LH 2 are inserted into the membrane after blockage of carotenoid synthesis in the crtI gene, or at different steps of BChl synthesis, the oligomeric complex is not formed.

Besides puc $\mathrm{C}$, additional open reading frames have been shown to have roles in pigment-protein assembly. J. Thomas Beatty's laboratory has demonstrated that LhaA, a homolog of PucC located $5^{\prime}$ to the reaction center $\mathrm{H}$ protein gene puhA in $R b$. capsulatus, is a major factor in LH 1 assembly (Young et al. 1998). Open reading frames, located $3^{\prime}$ to puhA and required for optimal LH 1/reaction center levels, include $\operatorname{orf} 214$ (Wong et al. 1996) and orf162b (Aklujkar et al. 2000), which have homologs in other species of purple bacteria. Their exact functions in the biogenesis of photosynthetic unit cores remain to be elucidated.

A cell-free translation system developed for studying the LH 1 assembly in $R b$. capsulatus has established that stable insertion of both the $\alpha$ - and $\beta$-polypeptides depends upon wild-type membranes, the chaperones DnaK and GroEL, and unknown, membrane-bound factors (Drews 1996b). During or before insertion into the membrane, the LH 1- $\alpha$ polypeptide is transiently phosphorylated at serine 2 , altering the charge distribution, which appears to be important for assembly. It is possible that insertion of LH 1 polypeptides may begin at specific docking sites, and that the nascent complex may interact with the reaction center. In comparison with Photosystem II of higher phototrophs, the reaction center/LH 1 complex has a simpler structure and genes responsible for assembly are known. Therefore, it is an excel- lent model to study the formation of membrane-bound supercomplexes at the molecular level.

\section{In vitro assembly of LH complexes}

As examined in detail by Paul Loach's group (Loach and Parkes-Loach 1995), treatment of LH1 complexes with $\beta$-octyl glucoside gives rise to the B820 subunit form $\left(\alpha_{1} \beta_{1} \mathrm{BChl}_{2}\right)$, which can be reconstituted into the oligomeric LH 1 complex after detergent dilution. Reconstitution has been achieved with several BChl $a$-type LH 1 s and the $\mathrm{BChl} b$-type of $B$. viridis, and with partially truncated or mutated polypeptides and structural analogs of BChl. Minimal requirements for reassociation include specific carbonyl and carbomethoxy groups of $\mathrm{BChl}$, the $\mathrm{Mg}$ atom and the conserved core region of the apoprotein, as well as stabilizing interactions by ion-pairing in the $\mathrm{N}$-terminal region.

Clearly, conditions for in vitro formation of $\mathrm{LH}$ 1 complexes differ from those for assembly in the living cell, where binding of cofactors and correct assembly of the apoprotein are dependent on additional unknown polypeptides. It is also necessary to avoid misfolding and binding of unrelated components interfering with assembly, which are not present in the in vitro system.

\section{The assembly of supercomplexes}

As noted above, in freeze-fracture replicas, reaction center/LH 1 complexes form a regular pattern of intramembrane particles. The possibility that these structures represent supercomplexes of reaction centers, cytochrome $c_{2}$ and the cytochrome $b c_{1}$ complex was first proposed by Pierre Joliot (Lavergne and Joliot 1991) as an explanation for their electron transport kinetics. A recent projection map of tubular membranes from an LH $2^{-}$mutant of $R b$. sphaeroides (Jungas et al. 1999) showed that supercomplexes consist of two C-shaped LH 1 arrays enclosing dimeric reaction centers, in possible association with a single $b c_{1}$ complex.

A role for PufX in the assembly of supercomplexes is suggested in Figure 5. The PufX protein, encoded by the pufX gene located in the pufQBALMX operon, is associated with isolated B875-reaction center core structures and is required for photosynthetic growth in $R b$. sphaeroides as shown in Dieter Oesterhelt's laboratory (Farchaus et al. 1992) and in Rb. capsulatus, as demonstrated by the Beatty group (Lilburn et al. 1992). The latter workers proposed that PufX functions in promoting $\mathrm{UQ} / \mathrm{UQH}_{2}$ exchange between sites 
A

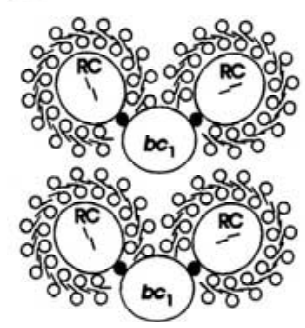

B

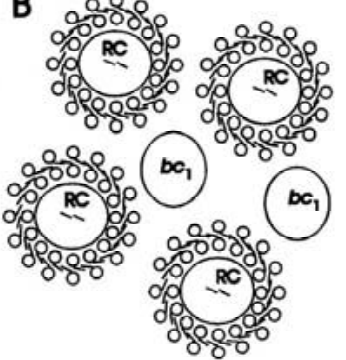

Figure 5. Model for the role of PufX in the organization of $\mathrm{LH}$ 1-reaction-center core complexes in $R b$. sphaeroides. (A) In the presence of PufX (solid circles), supercomplexes are formed consisting of two reaction centers (RC) and one cytochrome $b c_{1}$ complex $\left(b c_{1}\right)$; complete circularization of LH 1 (open circles) is prevented, thereby permitting UQ exchange. (B) In the absence of PufX, reaction centers are monomeric and LH 1 forms larger, closed annular structures. In addition to the projection map of photosynthetic units in a Rb. sphaeroides LH $2^{-}$mutant (Jungas et al. 1999), these models are based upon findings in $p u f \mathrm{X}$ deletion strains which include a 1.2-1.5-fold increases in the LH 1-reaction-center ratios (McGlynn et al. 1994), and the observation of a monomeric LH 1-reaction-center complex in sucrose gradients (Francia et al. 1999).

on the reaction center and $b c_{1}$ complexes, and this was established later for $R b$. sphaeroides (Barz et al. 1995). The finding was further supported by the localization of second-site suppressor mutants in the pufBA genes encoding the LH 1- $\alpha$ - and $\beta$-apoproteins (Lilburn et al. 1995), and the lack of a PufX requirement in the absence of LH 1 as shown in Neil Hunter's laboratory (McGlynn et al. 1994). These findings have suggested that in the absence of PufX, LH 1 tightly surrounds the reaction center and impedes $\mathrm{UQ} / \mathrm{UQH}_{2}$ movements and that the suppression of this defect results from a destabilization of LH 1, enhancing UQ exchange.

Linear dichroism measurements on oriented $\mathrm{LH}$ $2^{-} R b$. sphaeroides membranes indicate that PufX is also essential for conferring the correct orientation to the reaction center and for promoting long-range order to LH 1-reaction center arrays (Frese et al. 2000). Further detergent solubilization studies on $R b$. sphaeroides puf $\mathrm{X}^{-}$strains suggest that $\mathrm{PufX}$ is responsible for dimerization of the LH 1-reaction center complex (Francia et al. 1999). In recent reconstitution work, LH 1-PufX associations have also been demonstrated between the LH 1- $\alpha$ polypeptide and the core segment of the PufX transmembrane $\alpha$-helix (Parkes-Loach et al. 2001). Ultimately, elucidation of the atomic resolution structure of the isolated PufX protein should shed more light on this question.

\section{Acknowledgment}

We thank Willem H.J. Westerhuis for providing Figure 5 .

\section{Note \\ ${ }^{1}$ Comparisons of amino acid sequences deduced from the se- quences of structural gene with those of mature polypeptides have shown that cleavable $\mathrm{C}$-terminal sequences of 9-13 amino acids exist for the $\alpha$ - and $\beta$-apoproteins of Rs. rubrum LH 1 (Berard et al. 1986) and for the PufX protein (Parkes-Loach et al. 2001), but their role in the assembly process remains unknown.}

\section{References}

Aklujkar M, Harmer AL, Prince RC and Beatty JT (2000) The orf162b sequence of Rhodobacter capsulatus encodes a protein required for optimal levels of photosynthetic pigment-protein complexes. J Bacteriol 182: 5440-5447

Barz WP, Verméglio A, Francia F, Venturoli G, Melandri BA and Oesterhelt D (1995) The role of the pufX protein in photosynthetic growth of Rhodobacter sphaeroides. 2. PufX is required for efficient ubiquinone/ubiquinol exchange between the reaction center $\mathrm{Q}_{\mathrm{B}}$ site and the cytochrome $b c_{1}$ complex. Biochemistry 34: $15248-15258$

Bauer C, Buggy J and Mosley C (1993) Control of photosystem genes in Rhodobacter capsulatus. Trends Genet 9: 56-60

Berard J, Bélanger G, Corriveau P and Gingras G (1986) Molecular cloning and sequence of the B880 holochrome gene from Rhodospirillum rubrum. J Biol Chem 261: 82-87

Bowyer JR, Hunter CN, Ohnishi T and Niederman RA (1985) Photosynthetic membrane development in Rhodopseudomonas sphaeroides: spectral and kinetic characterization of redox components of light-driven electron flow in apparent photosynthetic membrane growth initiation sites. J Biol Chem 260: 3295-3304

Broglie RM, Hunter CN, Delepelaire, P, Niederman, RA, Chua N-H and Clayton RK (1980) Isolation and characterization of pigment-protein complexes of Rhodopseudomonas sphaeroides by lithium dodecyl sulfate/polyacrylamide gel electrophoresis. Proc Natl Acad Sci USA 77: 87-91

Clayton RK and Clayton BJ (1972) Relations between pigments and proteins in the photosynthetic membranes of Rhodopseudomonas spheroides. Biochim Biophys Acta 283: 492-504

Davidson E and Daldal F (1987) Primary structure of the $b c_{1}$ complex of Rhodopseudomonas capsulata. Nucleotide sequence of the pet operon encoding the Rieske, cytochrome $b$, and cytochrome $c_{1}$ apoproteins. J Mol Biol 195: 13-24

Deisenhofer J, Epp O, Miki K, Huber R and Michel H (1985) Structure of the protein subunits in the photosynthetic reaction centre of Rhodopseudomonas viridis map at $3 \AA$ resolution. Nature 318 : 618-624

Drews G (1996a) Forty-five years of developmental biology of photosynthetic bacteria. Photosynth Res 48: 325-352

Drews G (1996b) Formation of the light-harvesting complex I (B870) of anoxygenic phototrophic purple bacteria. Arch Microbiol 166: 151-159

Drews G (2000) The roots of microbiology and the influence of Ferdinand Cohn on microbiology of the 19th century. FEMS Microbiol Rev 24: 225-249 
Drews G and Golecki JR (1995) Structure, molecular organization, and biosynthesis of membranes of purple bacteria. In: Blankenship RE, Madigan MT and Bauer CE (eds) Anoxygenic Photosynthetic Bacteria, pp 231-257. Kluwer Academic Publishers, Dordrecht, The Netherlands

Farchaus JW, Barz WP, Grünberg H and Oesterhelt D (1992) Studies on the expression of the pufX polypeptide and its requirement for photoheterotrophic growth in Rhodobacter sphaeroides. EMBO J 11: 2779-2788

Francia F, Wang J, Venturoli G, Melandri BA, Barz WP and Oesterhelt D (1999) The pufX protein is involved in pseudodimerization of reaction center-antenna core complexes in Rhodobacter sphaeroides. Biochemistry 38: 6834-6845

Frenkel A (1954) Light-induced phosphorylation by cell-free preparations of photosynthetic bacteria. J Am Chem Soc 76: 55685569

Frese RN, Olsen JD, Branvall R, Westerhuis WHJ, Hunter CN and van Grondelle R (2000) The long-range supraorganization of the bacterial photosynthetic unit: a key role for PufX. Proc Natl Acad Sci USA 97: 5197-5202

Gibson LC, McGlynn P, Chaudhri M and Hunter CN (1992) A putative anaerobic coproporphyrinogen III oxidase in Rhodobacter sphaeroides. II. Analysis of a region of the genome encoding hem $\mathrm{F}$ and the puc operon. Mol Microbiol 21: 3171-3186

Hunter CN, Pennoyer JD, Sturgis JN, Farrelly D and Niederman RA (1988) Oligomerization states and associations of light-harvesting pigment-protein complexes of Rhodobacter sphaeroides as analyzed by lithium dodecyl sulfatepolyacrylamide gel electrophoresis. Biochemistry 27: 3459 3467

Jungas C, Ranck JL, Rigaud JL, Joliot P and Verméglio A (1999) Supramolecular organization of the photosynthetic apparatus of Rhodobacter sphaeroides. EMBO J 18: 534-542

Kaplan S, Cain BD, Donohue TJ, Shepherd WD and Yen GS (1983) Biosynthesis of the photosynthetic membranes of Rhodopseudomonas sphaeroides. Cell Biochem 22: 15-29

Karrasch S, Bullough PA and Ghosh R (1995) The 8.5-A projection map of the light-harvesting complex I from Rhodospirillum rubrum reveals a ring composed of 16 subunits. EMBO J 14: 631-638

Kiley PJ, Varga A and Kaplan S (1988) Physiological and structural analysis of light-harvesting mutants of Rhodobacter sphaeroides. J Bacteriol 170: 1103-1115

Kolber ZS, van Dover CL, Niederman RA and Falkowski, PG (2000) Bacterial photosynthesis in surface waters of the open ocean. Nature 407: 177-179

Lavergne J and Joliot P (1991) Restricted diffusion in photosynthetic membranes. Trends Biochem Sci 16: 129-134

Lilburn TG, Haith CE, Prince RC and Beatty JT (1992) Pleitropic effects of pufX gene deletion on the stucture and function of photosynthetic apparatus of Rhodobacter capsulatus. Biochim Biophys Acta 1100: 160-170

Lilburn TG, Prince RC and Beatty JT (1995) Mutation of the Ser2 codon of the light-harvesting B870 $\alpha$ polypeptide of Rhodobacter capsulatus partially suppresses the pufX phenotype. J Bacteriol 177: 4593-4600
Loach PA and Parkes-Loach PS (1995) Structure-function relationships in core light-harvesting complexes (LH 1) as determined by characterization of the structural subunit and by reconstitution experiments. In: Blankenship RE, Madigan MT and Bauer CE (eds) Anoxygenic Photosynthetic Bacteria, pp 437-471. Kluwer Academic Publishers, Dordrecht, The Netherlands

Marrs BL (1981) Mobilization of the genes for photosynthesis from Rhodopseudomonas capsulata by a promiscuous plasmid. J Bacteriol 146: 1003-1012

McDermott G, Prince SM, Freer AA, Hawthornthwaite-Lawless AM, Papiz MZ, Cogdell RJ and Isaacs NW (1995) Crystal structure of an integral membrane light-harvesting complex from photosynthetic bacteria. Nature 374: 517-521

McGlynn P, Hunter CN and Jones MR (1994) The Rhodobacter sphaeroides PufX protein is not required for photosynthetic competence in the absence of a light harvesting system. FEBS Lett 349: 349-353

Niederman RA and Gibson KD (1978) Isolation and physicochemical properties of membranes from purple photosynthetic bacteria. In: Clayton RK and Sistrom WR (eds) The Photosynthetic Bacteria, pp 79-118. Plenum Press, New York/London

Oelze J and Drews G (1972) Membranes of photosynthetic bacteria. Biochim Biophys Acta 265: 209-239

Parkes-Loach PS, Law CJ, Recchia PA, Kehoe J, Nehrlich S, Chen J and Loach PA (2001) Role of the core region of the PufX protein in inhibition of reconstitution of the core light-harvesting complexes of Rhodobacter sphaeroides and Rhodobacter capsulatus. Biochemistry 40: 5593-5601

Reed DW and Clayton RK (1968) Isolation of a reaction center fraction from Rhodopseudomonas spheroides. Biochem Biophys Res Commun 30: 471-475

Tichy HV, Albien KU, Gad'on N and Drews G (1991) Analysis of the Rhodobacter capsulatus puc operon: the puc $\mathrm{C}$ gene plays a central role in the regulation of LH 2 (B800-850 complex) expression. EMBO J 10: 2949-2955

van Niel CB (1931) On the morphology and physiology of the purple and green sulphur bacteria. Arch Mikrobiol 3: 1-112

Wong DKH, Collins WJ, Harmer A, Lilburn TG and Beatty JT (1996) Directed mutagenesis of the Rhodobacter capsulatus puhA Gene and Orf214: pleiotropic effects on photosynthetic reaction center and light-harvesting 1 complex. J Bacteriol 178: 2334-2342

Young CS, Reyes RC and Beatty JT (1998) Genetic complementation and kinetic analyses of Rhodobacter capsulatus ORF1696 mutants indicate that the ORF1696 protein enhances assembly of the light-harvesting I complex. J Bacteriol 180: 1759-1765

Youvan DC, Bylina EJ, Alberti M, Begusch H and Hearst JE (1984) Nucleotide and deduced polypeptide sequences of the photosynthetic reaction-center, B870 antenna, and flanking polypeptides from Rhodopseudomonas capsulata. Cell 37: 949-957

Zuber H (1990) Considerations on the structural principles of the antenna complexes of phototrophic bacteria. In: Drews $G$ and Dawes EA (eds) Molecular Biology of Membrane-Bound Complexes in Phototrophic Bacteria, pp 161-180. Plenum Press, New York/London 